\title{
Family-school relationships in immigrant children's well-being: the intersection of demographics and school culture in the experiences of black African immigrants in the United States
}

\section{Citation}

Dryden-Peterson, Sarah. 2017. Family-school relationships in immigrant children's wellbeing: The intersection of demographics and school culture in the experiences of Black African immigrants in the United States. Race Ethnicity and Education.

\section{Published Version}

http://www.tandfonline.com/doi/full/10.1080/13613324.2017.1294562

\section{Permanent link}

http://nrs.harvard.edu/urn-3:HUL.InstRepos:30802655

\section{Terms of Use}

This article was downloaded from Harvard University's DASH repository, and is made available under the terms and conditions applicable to Open Access Policy Articles, as set forth at http:// nrs.harvard.edu/urn-3:HUL.InstRepos:dash.current.terms-of-use\#OAP

\section{Share Your Story}

The Harvard community has made this article openly available.

Please share how this access benefits you. Submit a story.

Accessibility 
Title: $\quad$ Family-School Relationships in Immigrant Children's Well-Being: The Intersection of Demographics and School Culture in the Experiences of black African Immigrants in the United States

Author:

Sarah Dryden-Peterson (Corresponding Author)

Affiliation:

Harvard Graduate School of Education

Contact Details: $\quad$ Sarah Dryden-Peterson

Harvard Graduate School of Education

6 Appian Way

Gutman Library 457

Cambridge, MA 02138 USA

Tel: 617-495-8162/ 617-435-2344

Email: sarah_dryden-peterson@gse.harvard.edu

Bio: $\quad$ Sarah Dryden-Peterson leads a research program that focuses on the connections between education and community development, specifically the role that education plays in building peaceful and participatory societies. Her work is situated in conflict and post-conflict settings in subSaharan Africa and with African Diaspora communities in the United States and Canada. Dryden-Peterson is on the faculty of the Harvard Graduate School of Education. She previously taught middle school in Boston and founded non-profits in Uganda and South Africa. 


\title{
Title
}

Family-School Relationships in Immigrant Children's Well-Being: The Intersection of Demographics and School Culture in the Experiences of black African Immigrants in the United States

\begin{abstract}
This article explores the types of family-school relationships that promote academic, socioeconomic, and social and emotional well-being of black African immigrant children in the United States. The data are ethnographic, drawing on one year of participant observation and interviews at two elementary schools. The findings are also set within the context of an analysis of data from the New Immigrant Survey. The article identifies mechanisms by which relationships between black African immigrants and schools are created and argues that intersections between demographics and school culture are central, particularly as related to the possibilities for relational power, which can allow parents and school staff to transcend persistent inequalities of race and discrimination.
\end{abstract}

\section{Keywords}

Migration, African immigrants, family-school relationships, relational power 


\section{Family-School Relationships in Immigrant Children's Well-Being: The Intersection of Demographics and School Culture in the Experiences of Black African Immigrants in the United States}

Relationships between schools and families have become a major concern in debates over narrowing academic achievement gaps in the United States. The value of strong relationships between schools and families is increasingly apparent, yet the wide-spread presence of antagonistic family-school relationships has been well-documented, especially for immigrant families (Horvat, Weininger, and Lareau 2003, Olivos 2006, Warren et al. 2009). Public debates have been characterized by blaming rhetoric: parents who 'don't care' about their children's education or schools that are unresponsive to cultural differences and the needs of families.

A core element of the antagonism, and blaming, appears to stem from new situations in which many schools and families find themselves and the challenges involved in created relationships that span the divides. For schools, the demographics of public schoolchildren have changed rapidly over the past several decades. The proportion of K-12 students in the US who are foreign-born or second generation has increased rapidly (Fix and Capps 2005, U.S. Census Bureau 2011) such that by 2050, children of colour are projected to account for 60 per cent of children under the age of 18 , and children with at least one foreign-born parent will account for 30 per cent (Pasel 2011). Most teachers, however, continue to be white (Noguera 1996), and while the number of foreign-born teachers is unavailable, about half of teachers work within 150 miles of the place they were born (Feistritzer 2011, 55).

Most immigrant families are in a similarly unfamiliar educational environment, one in which engaging with schools is a new experience. Educational experiences are, of course, 
particular to local, national, and regional contexts, yet many immigrant families describe being raised in cultures in which there was little interaction between schools and families and in which the school had complete authority and responsibility over academic learning. Further, the content of curriculum and pedagogy can be remarkably different in the US than in school systems immigrant families experienced as children. An example from my fieldwork is illustrative: one Nigerian mother commented that while she did 'spelling' at school, her first grade daughter does 'blends,' or 'phonemic awareness,' or 'beginning reader requirements.' She explained also that 'in Nigeria, if you don't listen to your teacher, you will get a -,' at which point her daughter interrupted her and said, 'community violation?' The mother laughed at first to recognize the deep cultural differences between her own educational experience and her daughter's, and then continued: 'no, you won't get a community violation. Your teacher will get a long stick.'

It is difficult for immigrant families and schools to build relationships across multiple lines of difference, including language, culture, race, country of origin, and educational norms of family participation and discipline (will my child get a community violation, or will she get caned with a long stick?). With few exceptions, most studies have examined either how families could be more effective at building relationships with schools or how schools could be more welcoming places for families. This study, by contrast, brings together family characteristics and school characteristics to examine their intersections. The unique comparative analysis of one immigrant group in the US - black Africans - across two divergent school settings allows for a focus on how school culture can foster or impede school-family relationships and the extent to which these relationships are mediated by individual demographic characteristics.

\section{Conceptual Framings}




\section{Immigrant Children's Well-Being}

I divide immigrant children's well-being into three analytic categories: academic wellbeing, socio-economic well-being, and social and emotional well-being. Research is clear that family engagement improves academic achievement, including at the elementary school level (Fan and Chen 2001, Lee and Bowen 2006, Jeynes 2003). Yet not all forms of family participation foster better academic outcomes. Some institutional forms of family involvement, such as fundraising or attending open houses, are not as important to achievement as more private forms of involvement that focus on the development of skills and knowledge, especially through help with homework (Gonzalez 2005, 122). Working together, teachers and immigrant families can engage in the kind of communication that links school- and home-based learning to improve academic achievement.

Family engagement with schools is also positively related to immigrant children's socioeconomic well-being. Institutions can play critical roles in fostering access to tangible benefits for immigrant families, related to economic security, housing, health care, and food (Warren, Thompson, and Saegart 2001). The potential for schools to play this role is widely accepted, even if not often adopted in practice (Dryfoos and Maguire 2002, López, Scribner, and Mahitivanichcha 2001, 282).

Finally, family engagement with schools is connected to immigrant children's social and emotional well-being. Schools often operate from within a culture of power that focuses on the deficits rather than the assets of immigrant families such that immigrant children feel isolated and alienated from school staff and native-born peers. Family engagement can help to transform this unhealthy culture within schools. Some researchers have argued for an approach to family engagement based on 'funds of knowledge' in which teachers are active learners about the 
cultural and cognitive resources of their students' families and can incorporate these assets into the classroom (Moll et al. 1992). Embedded in relationships between their families and teachers that are based on collaboration and trust, immigrant children can be socially and emotionally supported as part of a community.

\section{Structural and Relational Approaches to Power in Family-School Interactions}

Family-school relationships that improve the multiple facets of well-being of immigrant children are difficult to cultivate (Warren et al. 2009, Shirley 1997). Strategies that schools and teachers can use to create these types of relationships can be divided into two inter-related categories: structural and relational.

Structural strategies include institutional policies and practices that facilitate meaningful conversations between school staff and families. Examples include holding substantive meetings on days and at times when families are able to attend, making sure that families know that they are needed for parent-teacher conferences, and holding these conferences 'any time and any place' (Lawrence-Lightfoot 2003, 224). Only with implementation of these structural strategies can relational strategies for family-school interactions develop, i.e. those that focus on relationships between schools and families.

With common care for and concern about a child, families and teachers already share the basis for relationships that are 'deeply mutual' (Loomer 1976). Yet there is often a mismatch between immigrant families' modes of communication and interaction and the culture of schools (Roubeni et al. 2015), which many scholars describe schools as white, middle-class institutions that reward white, middle-class behaviors (Horvat, Weininger, and Lareau 2003, Fine 1993, see also Knight, Roegman, and Edstrom 2015 on black African students navigation of higher 
education in the US). Immigrant families often have informed knowledge about schools and school practices (Mapp and Hong 2010, Hong 2011, Velez 2012), but can be made by schools to feel like pawns rather than equal contributors to the relationship (Fine 1993).

Understandings of unilateral and relational power provide insights into how schools and immigrant families might bridge these divides to build relationships that foster the well-being of immigrant children. Gendron characterizes unilateral power as 'a zero-sum game, following the Weberian definition of power as the "probability that one actor within a social relationship will be in a position to carry out his own will despite resistance".' Relational power, on the other hand, is 'collective... [and] its deployment is viewed as a means to effect cooperation between persons that can synergistically increase their ability to achieve mutually agreed-upon ends' (Gendron 2006, 6). Relational power therefore involves the capacity to influence others and be influenced by others. To achieve relational power necessitates 'deeply mutual relationships' that involve communal or relational concepts of the self (Loomer 1976, 13-15), transcending race, class, education level, and immigration status. Building relational power between schools and immigrant families requires altering the structures and spaces of family-school interactions and re-conceptualizing both their nature and content so that families and school staff have this capacity to influence and be influenced by each other.

Through the lens of these structural and relational approaches to power, the experiences of black African immigrant families at two schools provide an opportunity to investigate theoretical puzzles around the building of family-school relationships, particularly as related to the intersection of school culture and demographic characteristics such as immigration patterns and pre-migration characteristics such as parents' education level and English language fluency, as well as racialization and discrimination. 
Black African Immigrants in the United States

Compared to immigrants overall, black African immigrants are more likely to be recent immigrants to the US. In 2009, 48 per cent of the Africa-born had arrived in the US in 2000 or later, with only slightly under 10 per cent arriving prior to 1980 (McCabe 2011). Black African children are usually the first generation in US schools. They are also more likely to enter as refugees (22 per cent compared to 13 per cent of all immigrants) or on diversity visas (24 per cent compared to 5 per cent) (Capps, McCabe, and Fix 2011, 8). Refugees and diversity immigrants are under-represented in the US immigrant population and hence have relatively few co-ethnic colleagues in the country before their arrival.

In general, black African immigrants have higher levels of education: 42 per cent of black African immigrants age 25 or older have at least a four-year college education compared to less than 30 per cent of other immigrant and US-born adults. At the same time, there are significant numbers of black African immigrants, particularly refugees, who have less than a high school education, and some who lack formal schooling entirely (Capps, McCabe, and Fix 2011, 12).

The population of black African immigrants is also bifurcated in terms of Englishlanguage skills. Overall, 70 per cent of black African immigrants are fluent in English, giving them a significant advantage in communicating and building relationships with their children's teachers (Olivos 2006, Diaz Soto 1997). Yet only 21 per cent of those who are fluent speak English at home; for the remaining 49 per cent, English is not a mother tongue but an additional language, usually learned during formal schooling in their home countries. 
An additional salient factor in the development of family-school relationships for black African immigrants is the entrenched racial hierarchy of US society. The 'proximal host' theory posits that native-born white Americans would categorize black African immigrants as African Americans, a categorization the immigrants might reject or embrace (Mittelberg and Waters 1992). Arthur (2000) and Traoré \& Lukens (2006) suggest that black African immigrants often attempt to distance themselves from African Americans in terms of where they live, how they dress, and the ways in which they talk in order to avoid the negative stereotyping and racial discrimination they associate with being labeled as African American (cf. Waters 1994). Despite these strategies to avoid racial discrimination, black African immigrants find it difficult to escape racial prejudice. In the US labor market, for example, black African immigrants earn 19 per cent less than white African immigrants, controlling for relevant characteristics such as country of origin and educational attainment (Dodoo and Takyi 2002). There is reason to believe that this discrimination may transfer to other spheres of interaction, including between black African immigrant families and their children's schools.

Immigration patterns, pre-migration characteristics, and racialization of black African immigrants to the US suggest both possibilities and challenges in building relationships between families and schools. The findings from this study point to the mechanisms by which reciprocal and meaningful relationships between schools and black African immigrant families can be built and sustained. In particular, the study suggests ways in which demographic factors and school culture factors interact to mediate both the building of these relationships and their impacts on immigrant children's well-being.

\section{Methods and Data Sources}


The data presented in this article was collected during 41 weeks of participant observation during the 2007-2008 school year in each of two schools in Massachusetts, a state that is home to 5.4 per cent of African immigrants in the US and where Africans are the fastest growing foreign-born population (Bump, Lowell, and Pettersen 2005). The schools are referred to as Boston Elementary and Merrimack Valley Elementary. ${ }^{1}$ The observations were purposefully open-ended and involved full days spent in the schools to understand routines and the daily conversations and interactions that make up the culture of a school. There were also more formal elements to the participant observation, including classroom observations, shadowing secretaries, observing parent-teacher interactions at drop-off and pick-up, attending 'Back to School' nights, holiday concerts, fundraising events, parent meetings, and expositions of student work. Companion to the participant observation were in-depth interviews with black African immigrant parents at each school $(\mathrm{n}=17)$ and interviews with long-time resident teachers, school administrators, and community leaders $(\mathrm{n}=24)$, each lasting approximately two hours. Interview and observation data were supplemented with review of documents such as schooladministered surveys, standardized test scores, and school newsletters. All of the family interviews were with biological parents, and so I use the term parent when presenting data from the schools.

My analytic strategy involved the development of a coding system of emic codes that emerged inductively from the participants and etic codes that I assembled deductively from the literature (Strauss and Corbin, 1998). I coded all of the interviews transcripts and observational fieldnotes line-by-line, using classical, free, and in vivo coding processes (Strauss and Corbin, 1998; Miles and Huberman, 1994). To interpret the findings, the various data sources were triangulated and compared. While the data presented here are necessarily 'snapshots' of 
particular moments in the on-going life of each school, they are representative of the interactions between schools and families that I observed over the course of one academic year and of the meaning that black African immigrant parents and school staff ascribed to these interactions in interviews.

To provide national context, I use both publicly available and restricted data from the nationally-representative New Immigrant Survey (NIS) ${ }^{2}$ to describe the ways in which subSaharan African parents with children attending elementary school ( $n=33)$, defined as kindergarten through sixth grade, participate in their children's education and how this participation compares with that of all immigrants $(\mathrm{n}=796)$. The NIS is a nationally representative survey of immigrants granted legal permanent residency (LPR) between May and November 2003 with a probability sample drawn from US government records.

\section{Findings}

\section{School Demographics}

This study compares a school in large city and traditional immigrant destination (Boston) with a school in a small city and comparatively newer immigrant destination (Merrimack Valley). The two schools were similar in several ways (see Table 1). They had the highest proportions of black African immigrant students in their districts; they were small; they had students from over 30 countries; and they housed Sheltered English Immersion (SEI) programs for children from language backgrounds that were not highly represented in the districts. SEI programs were exclusively for students who were limited in English with the goal of transitioning them as quickly as possible to a mainstream, grade-level class. According to 
school-administered surveys, half of the students in each school spoke a language other than English as their first language.

The vast majority of students at both schools was eligible for free or reduced lunch. The schools were located in predominantly white neighbourhoods in their respective cities, middleincome in Boston and low-income in Merrimack Valley. The schools drew students from neighbourhoods across their respective cities, however, through school assignment that used bussing programs in order to desegregate schools in racially segregated residential areas. Both of the schools fell within the 'Needs Improvement' category of No Child Left Behind (NCLB), indicating low performance on standardized tests in English Language Arts and mathematics.

The schools differed from each other in terms of racial and ethnic demographics, reflecting the cities in which they were located. Boston Elementary students were predominantly black and Latino, while Merrimack Valley Elementary had large populations of Latinos, whites (many of whom were newly arrived from Eastern Europe), and Asians. Further, at Boston Elementary, 33 per cent of the black students were African immigrants, whereas at Merrimack Valley Elementary, 92 per cent of black students were African immigrants.

\section{[TABLE 1 HERE]}

\section{Black African Immigrant Parent Demographics}

Despite certain similarities, black African immigrant parents at Boston Elementary and Merrimack Valley Elementary differed from each other in terms of their countries of origin, religions, and some socio-demographic characteristics that may impact child well-being (see Table 2). The parents at Boston Elementary were primarily from Somalia and Ethiopia in the Horn of Africa, reflecting the large populations of these African groups in Boston. Black African 
immigrant parents at Merrimack Valley were primarily from West Africa and East Africa. Related, all of the black African immigrant parents at Merrimack Valley Elementary were Christian, whereas more than half at Boston Elementary were Muslim (the remainder were Christian).

Black African immigrant parents at both schools largely came to the US as refugees (30 per cent in each site) or on diversity visas. Reflecting overall immigration trends, all of the parents involved in this study were born in Africa, however, the majority of their children were born in the US and form part of the second generation. The few children who were first generation immigrants came to the US at a very young age. Black African immigrant parents at Boston Elementary had been in the US slightly longer than their counterparts at Merrimack Valley, yet were less likely to describe themselves as 'fluent' in English. Nevertheless, all of the black African immigrant parents in both schools reported English proficiency. Black African immigrant parents with children enrolled at Merrimack Elementary generally had better employment outcomes than those with children at Boston Elementary, despite the fact that the majority of parents at both schools had at most a high school education. Virtually all of the working black African immigrant parents at each school worked in the service-sector and none, including those with professional skills, were employed in management positions or occupations that demand high skills or credentials.

Most parents at both schools were raising their children in two parent homes. Many of the black African immigrant parents at Boston Elementary lived in public housing compared to none of the Merrimack Valley parents. Conversely, some of the black African immigrant parents at Merrimack Valley were homeowners compared to none of the Boston Elementary parents. The 
different housing patterns likely reflected the great expense of housing, both for rent and purchase, in Boston compared to Merrimack Valley.

Taken together, this analysis of the demographics of black African immigrant parents suggests that their children enrolled at Boston Elementary may be more likely to confront hardship -related to English fluency, parental unemployment, and residential stability - than those at Merrimack Valley.

[TABLE 2 HERE]

\section{Relationships between Schools and black African Immigrant Parents}

Data from the New Immigrant Survey (NIS) provide for a descriptive account of how a nationally-representative sample of sub-Saharan African parents participate in their children's education and how this participation compares with that of all immigrants. Overall, African immigrants participate at higher rates than other immigrants on all measures associated with family-school interaction (see Table 3). Although the differences are small, African parents sampled in the NIS are most different from other immigrant parents in the aspects of participation in schools that have been found to impact directly on academic development: visiting class, checking homework, and holding high expectations for college completion.

Ethnographic data from the case studies of Boston Elementary and Merrimack Valley Elementary corroborate high levels of school participation by black African immigrant parents, which distinguishes this group from other parents at the same schools. Similar to sub-Saharan African parents in the NIS, the black African immigrant parents at the two schools exhibited high expectations for their children's educational success, including college completion. They also universally reported dedicating time on a daily basis to assisting with and checking homework. 
Tara, ${ }^{3}$ a first grade teacher at Merrimack Valley Elementary, described what she called the 'support' from home: '.. [black African students'] homework is done, their homework is checked, their homework has been corrected, they have more of a routine [than other students].' Conversations with black African immigrant parents at Boston Elementary and observations in their homes revealed similar commitment to their children's homework.

Family-School Relationships in African Immigrant Children's Well-Being

While parent participation was high in both case study schools, the data from Boston Elementary and Merrimack Valley Elementary illustrate contrasting types of relationships between schools and black African immigrant families. In summary, black African immigrant families at Boston Elementary reported frequent cultural misunderstandings and struggles for authority with school staff whereas parents with children enrolled at Merrimack Valley characterized their relationships with school staff as mutually respectful, trusting, and collaborative. How do these types of family-school relationships influence black African immigrant children's academic, socio-economic, and social and emotional well-being in each school setting?

Academic Well-Being. Black African immigrant parents described being pleased with the kind of instruction their children received at Merrimack Valley Elementary. Patrick, from Kenya, commented in detail on how his daughter's teachers were covering all aspects of the grade-level syllabus, and Goretti, from Ghana, marveled at how quickly her first grade son, Oscar, was learning: 'Not a year and he started to write.' I observed Oscar reading aloud a fifty-page easy reader book about a seal who spends the day getting to know the world outside his zoo home. He asked a few questions about pronunciations of words, knowing when he was not getting it quite 
right; his intonation and rhythm conveyed meaning, and he answered all of my questions about the story. Oscar's reading development was a joint preoccupation of his teachers, his parents, and the Principal. All children at Merrimack Valley worked in small literacy groups of no more than eight children every day, for 40 minutes. All adults in the building took part in leading these groups, from the Principal to the social worker to the part-time tutor to the school nurse. They also led similarly structured small-group math programs every day for the same amount of time.

Despite this kind of personal attention to the learning of each student, Merrimack Valley Elementary in general struggled to help children achieve academically, as measured by standardized tests. On the third grade Massachusetts Comprehensive Assessment System (MCAS) tests, Merrimack Valley ranked below 900 out of 1002 schools in the state in English Language Arts (ELA) and just above 900 out of 1001 in math (Boston Globe 2008b). In ELA, for example, 76 per cent of third graders and 83 per cent of fourth graders were in the 'Needs Improvement' or 'Warning/Failing' categories (Boston Globe 2008a). These challenges were not unique to immigrant students at Merrimack Valley but pervaded the school, as is common in schools serving children of colour and children living in poverty across the US, and in other contexts such as the United Kingdom, Canada, and Australia (see, for example, Markose and Simpson 2016, Yosso 2005).

The instructional focus at Boston Elementary was squarely on preparation for this kind of standardized test, an unfortunately common approach in high-poverty schools serving children of colour (Lunneblad and Dance 2014, Jennings and Bearak 2014). Fifth grade teacher Dave described a time when every child in the school was going to spend one hour responding to a writing prompt, a task required of children on the fourth grade MCAS. Dave had a new student in his class who had just arrived in the US two weeks prior, had never been to school anywhere 
before, and spoke no English. Dave asked for this student to be excused from the writing prompt and to spend the hour instead one-on-one with Dave. The principal refused saying that every child must participate. Dave looked angry when he told the story: 'This kid arrived two weeks ago in the country, he can't do this!' Dave described a pervasive feeling at the school, even among adults who themselves were immigrants, of 'well, I've made it by pulling myself up by my bootstraps, so you should do the same.'

Despite a focus on raising student achievement on standardized tests, MCAS results at Boston Elementary were as low as those at Merrimack Valley. On third grade MCAS assessments, Boston Elementary also ranked below 900 out of 1002 schools in the state in ELA and well below 900 out of 1001 in math (Boston Globe 2008b). In ELA, 64 per cent of third graders and 86 per cent of fourth graders were in the 'Needs Improvement' or 'Warning/Failing' categories (Boston Public Schools 2007).

On the face of it, these data suggest that the two different approaches to family engagement and to learning in the schools do not make measurable differences in academic outcomes. However, a different picture emerges of how black African immigrant students were faring at each school when compared to their peers. At Boston Elementary, teachers explained that the low aggregate MCAS scores for the school as a whole were quite representative of black African students' achievement as well. (Teachers had access to individual student achievement data from the MCAS and could thus draw conclusions about the performance of black African immigrant students compared to other students in the school.)

At Merrimack Valley, on the other hand, teachers explained that black African immigrant students tended to do better than the average, having some of the highest scores in the school on the MCAS and other standardized tests. The teachers at Merrimack Valley also focused on 
perfect attendance as an indicator of student success, emphasizing to students both that they could not learn if they were not present and that they could have control over their own achievement. (Given the length of time needed to show gains in language acquisition and on achievement tests administered in English, this type of engagement in school may provide an important short-term measure of school success. ${ }^{4}$ ) Just as black African immigrant parents were, in general, more involved in the school than other parents and more likely to spend time with children doing homework, black African immigrant students as a group had better attendance records than other students. At several monthly all-school Assemblies, all of the African students in the school were recognized for perfect attendance; and, out of the nine children who had perfect attendance for 180 days, every single day of the school year, four of them were black African immigrant students.

Socio-Economic Well-Being. Black African immigrant parents at both Boston Elementary and Merrimack Valley Elementary sought information and resources from their children's schools that would help them care for the socio-economic needs of their children in the US. At Boston Elementary, black African immigrant parents explained that they had attempted to interact with school staff around this facet of their children's well-being, especially related to English as a Second Language (ESL) classes and housing. They reported, however, that they had not been able to find this kind of support through the school. Several teachers described not having the time to attend to these issues when they were already overworked.

On the other hand, Merrimack Valley Elementary provided socio-economic support for black African immigrant families. For example, the school nurse started and managed a 'store' filled with an abundance of free, recycled clothes, shoes, and especially winter jackets, where children and parents could visit when they were in need. Several black African immigrant 
parents described how access to these material resources kept their families warm in the winter. Goretti, from Ghana, recounted how, at Christmas, the principal asked her for a list for each of her children of 'everything they need.' In partnership with the local hospital, the school delivered to Goretti and her family baskets full of toys and clothing. These practices were not systematic, but they had become commonplace as part of the culture of the school.

Perhaps most importantly, Lauren, the Principal at Merrimack Valley recognized the role of the school as taking 'one piece of worry' - the worry of a good education - 'off the parents' shoulders... [so] they can then concentrate on whether they need to find better housing or a job.' Black African immigrants experienced this commitment and described how their relationships with their children's teachers and other school staff allowed them to be assured that their children were well-cared for, an assurance that contributed to their own contentment as well as created the time and mental space for them to focus on the family's financial stability.

Social and Emotional Well-Being. At Boston Elementary, black African immigrant children described feeling isolated and misunderstood. Shalawn, co-chair of the school's parent council, described the relationship between parents and the school as one of having on "boxing gloves." The parents of Charity, a fifth grade student, found the relationships with the Principal and teachers so straining, they withdrew their daughter from the school. Barbara, Charity's teacher, was unable to connect with this family. She said that "he [Charity's father] does not know how to parent in this world." Kayla, the kindergarten teacher in her first year at the school, remarked that she regretted how parents are told to interact with the school and their children rather than invited to contribute their ideas. She said, "the pressures are put on for other things, [so] it's not how can we get parents involved but it's how can we tell parents how to support their children through the year." 
A similar lack of connection was evident in that even by the end of the school year, many teachers at Boston Elementary did not know their students' countries of origin. For example, Courtney, a fourth grade teacher revealed that she thought one of her students, Zahir, might be from Africa but that she really had 'no idea.' In fact Zahir's family was from Republic of the Sudan but he was born elsewhere; this conversation never took place between Zahir and his teacher. The lack of knowledge of individual students appeared in other ways at Boston Elementary as well. When asking comprehension questions about the story she was reading aloud, Michelle, the literacy coach apologized to one student for having forgotten his name: 'Paulo,' he said smiling. 'Ra-ulo?', she pinched up her nose and rolled her eyes as she said it. Paulo looked embarrassed and did not contribute further to the conversation. When asked about this interaction, Michelle explained that her main focus was 'improving [the students'] skills.' At Merrimack Valley, teachers had much greater knowledge of their students' cultural backgrounds. For example, Emma, the lead English as a Second Language teacher, described her students as Kikuyu speakers, not only identifying the country from which they came (Kenya) but also the tribe and language group. Moreover, teachers at Merrimack Valley Elementary knew each child by name. At the last all-school Assembly of the year, Principal Lauren presented each student with a medal and a book for summer reading. She did not read the names of the children from a list, but simply called their names as they approached her, in any order. She knew every single student. Black African immigrant parents, like Annette and Catherine, from Kenya, Clemance, from Liberia, and Kofi, from Ghana, had this same familiarity with Merrimack Valley teachers. I observed them calling each teacher by name and making reference to the teachers' children or grandchildren whom they had met at school events. 
In addition, teachers intentionally strived to connect the social and emotional support that parents provided with a sense of belonging and pride in learning that they cultivated at school. For example, at the third grade poetry coffeehouse, every child had an adult present as their own special guest and cheerleader. If parents did not respond to the original invitation sent home, the teachers called them to encourage participation. If a parent could not attend, the teacher worked with the parent to arrange for a sibling or a former teacher to join the child. Sonia, from Cameroon, received a letter and then a phone call, and then a reminder just the day prior. The most important form of communication, though? My son 'would have killed me if I did not turn up!' Another black African immigrant father, Dela, from Kenya, left his workplace south of Boston early in order to get to the event on time, remarking that he "would not have missed it for the world.' As the students were set to begin reading their poems, a third grader from Cameroon said something to his teacher with a worried look on his face: his Mom was not here yet. Sue, his teacher whispered to him: '2:15pm, she said she would be here, and she will,' and she gave him a squeeze. She quickly changed around the order of presentations so that he could read last. His mother and sister walked in just in time to hear him read.

This interconnectedness allowed black African immigrant children to feel that they had a community of caring adults surrounding them, supporting them, nurturing them, and protecting them, all essential elements of children's social and emotional well-being.

\section{Discussion: Intersection of Demographics and School Culture}

The starting point for building relationships in both case study schools was a shared interest in children. And yet the relationships between black African immigrant parents and school staff at Boston Elementary and Merrimack Valley Elementary were markedly different in 
their structure and content, as well as in their impacts on children's academic, socio-economic, and social and emotional well-being. There are two categories of explanatory factors that I explore in turn, those related to demographics and those related to school culture.

Demographic factors were relevant at two levels: the level of the parents and the level of the school. At the level of the parents, Table 2 points to several critical differences between black African immigrant parents at the two schools, particularly related to religion, language, and poverty. Whereas all of the black African immigrant parents at Merrimack Valley were Christian, half at Boston Elementary were Muslim. There is evidence to suggest that Muslim immigrants feel more alienated from schools than other immigrants (El-Haj 2002), given, for example, the frequent lack of space for prayer, misunderstandings related to religious practices, and to stereotyping of Muslims by peers and school staff, particularly after September $11^{\text {th }}$. In this study, black African immigrants at Boston Elementary, whether Christian or Muslim, were similarly unlikely to be able to build relationships with school staff.

Language fluency interfered with relationship-building between families and school staff. All but one of the black African immigrant parents at Merrimack Valley described themselves as 'fluent' in English, versus a smaller two-thirds at Boston Elementary. Sana, from Somalia, explained how the large parent meetings held at Boston Elementary were difficult for her: Sometimes if I go to the school, if they talk, like a lot of parents they come in, and they talk ... I can't say [anything]. They didn't say ‘don't say nothing,' but I feel bad because my English is not good. Also, if they have a paper and they want people to read and write, I feel sad because I don't know how to read and write in English.... If they give me time to sit and talk to them, maybe one person or two people, then I tell them whatever I want.... Last year, at Open House, everyone 
they talk for what they want and what they believe. I didn't try, I can't try even.

I'm embarrassed.

Sana had a barrier of language that impeded her participation in large group settings, which did not prove to be an issue for black African immigrant parents with greater fluency in English, who spoke their minds at these types of meetings. Nevertheless, black African immigrant parents at Boston Elementary who spoke fluent English described being similarly constrained in their ability to engage relationally with school staff, as the kind of interactions in large group settings that Sana experienced did not prove to be a pathway to building these relationships.

The role that poverty plays in the differences in relationships between black African immigrant parents and school staff at the two schools is more difficult to assess. Family income information was not available for research participants. However, the high unemployment rate of black African immigrant parents at Boston Elementary (43 per cent) indicates the likely financial precariousness of this group of parents. While none of the Merrimack Valley parents worked in highly skilled-jobs, they all had stable employment. All of the unemployed parents at Boston Elementary were preoccupied with looking for work. Yet, they continued to prioritize attention to their children's homework and to engaging with the school, even if they struggled to build relationships, just as did the employed parents at Boston Elementary.

At the level of the school, there was an important difference in the geography of residence of students that may help to explain the types of relationships built at each school. At both Boston Elementary and Merrimack Valley Elementary, most students arrived by bus from all neighbourhoods of their respective cities, given special programs at both schools for students from low incidence language groups as well as desegregation bussing. The sizes of the cities and the nature of their transportation systems, however, meant that the spaces between students' 
homes and the two schools varied greatly in terms of both distance and time. Black African immigrant parents at Boston Elementary reported relying primarily on public transportation, and for most of them the journey to school took more than one and a half hours. In Merrimack Valley, owning a car was less expensive in terms of insurance payments and parking, as well as a necessity given public transportation schedules and the shift work that most black African immigrant parents did. For the half of black African immigrant parents with access to a car, the journey to school from home was no more than 20 minutes; with this ease of access, parents at Merrimack Valley could be present at the school more often.

Table 1 points to an additional difference at the school level that may impact the building of relationships between black African immigrant parents and school staff. Only one third of the black students at Boston Elementary were African immigrants, versus over 90 per cent at Merrimack Valley. In this context, black African immigrant parents at Merrimack Valley described being perceived as 'African' by teachers and other school staff. At Boston Elementary, black African immigrant parents reported being labeled as 'African American' by teachers and school staff, and therefore ascribed a pre-determined racial identity often associated with negative stereotyping and racial discrimination (cf. Waters and Jiménez 2005, 117). As Mulgan argues, immigrants read these kinds of interactions to get a sense of whether they belong or will be 'ostracized and rejected' (2009). Building relationships with school staff at Boston Elementary was difficult for all parents, no matter their race, language, or nativity. Yet the racial context that lent itself to misrecognition of Africans as African Americans proved an additional barrier for black African immigrant parents in building relationships with teachers at Boston Elementary. Conversely, the immediate assumption that black families at Merrimack Valley were African and not African American was interpreted as an important signal to black African 
immigrant families of their authentic belonging.

\section{Conclusions and Implications}

Building relationships between black African immigrant parents and school staff was complicated by racial, socio-demographic, and residential differences between black African immigrant parents and school staff. The school culture of Boston Elementary seemed to make these barriers insurmountable. While the context may be demographically slightly less challenging, Merrimack Valley Elementary demonstrated the role that school culture can play in mediating the effects of these potential barriers to building relationships between black African immigrant parents and school staff.

While black African immigrant parents at Merrimack Valley faced many barriers associated with establishing productive family-school interactions, strong institutional guidance and support created a school culture that embraced parent engagement. Black African immigrant parents described being made to feel welcome at the school; they were not only invited but strongly encouraged to participate in school events focused on children's learning; teachers sought their input in discussions about children's learning and behavior; and they felt as if they were equals in their interactions with school staff. Through these relationships, the mutual care that they had for the children was made visible to both parents and teachers.

Critical was the substance on which black African immigrant parents and school staff interacted. The Boston Elementary Principal described that she primarily interacted with black African immigrant parents around issues of discipline. The parents described these interactions as occurring within power relations that made them feel uncomfortable and alienated from the process of their children's education. 
Staff members at Merrimack Valley focused their interactions with families on something they knew transcended cultural differences: care of children. These elements of school culture sent confirming and recognizing signals to black African immigrant parents at Merrimack Valley, creating conditions for the building of relationships between parents and school staff that were relational in structure and in content and fostered the well-being of black African immigrant children. Yet the academic, socio-economic, and social and emotional benefits of family-school relationships in evidence for the particular population of black African immigrant families at Merrimack Valley were not universal among other families at the school. A school culture that fosters family engagement was not enough to cultivate all children's well-being. The benefits of family-school relationships are indeed a two-way street, necessitating mutual and reciprocal investment by school staff and family members.

\section{Notes}

\footnotetext{
${ }^{1}$ The name of the smaller city is a pseudonym, honoring the request to protect the identity of the school district.

${ }^{2}$ Jasso, Guillermina, Douglas S. Massey, Mark R. Rosenzweig and James P. Smith. 'The New Immigrant Survey 2003 Round 1 (NIS-2003-1) Public Release Data and Restricted Data.' March 2006. Retrieved 9 April 2008. Funded by NIH HD33843, NSF, USCIS, ASPE \& Pew. http://nis.princeton.edu.

${ }^{3}$ All names are pseudonyms.

${ }^{4}$ I am indebted to Carola Suárez-Orosco for this observation.
} 


\section{References}

Arthur, John A. 2000. Invisible sojourners : African immigrant diaspora in the United States. Westport, Conn.: Praeger.

Boston Globe. 2008a. "2008 MCAS Results: [Merrimack Valley] Public Schools School-bySchool Results.", accessed January 23. http://www.boston.com/news/special/education/mcas/scores08/index schools.htm.

Boston Globe. 2008b. "Top-Scoring Schools on the 3rd Grade MCAS.". The Boston Globe, accessed January 19. http://www.boston.com/news/special/education/mcas/scores08/3rd top schools.htm.

Boston Public Schools. 2007. [Boston] Elementary School Report Card. Boston: Boston Public Schools.

Bump, Micah N., B. Lindsay Lowell, and Silje Pettersen. 2005. "The Growth and Population Characteristics of Immigrants and Minorities in America's New Settlement States." In Beyond the Gateway: Immigrants in a Changing America, edited by Elzbieta M Gozdziak and Susan F. Martin. New York: Lexington Books.

Capps, Randy, Kristen McCabe, and Michael Fix. 2011. New Streams: Black African Migration to the United States. In Improving US and EU Immigration Systems. Washington, DC: Migration Policy Institute, European University Institute.

Diaz Soto, L. 1997. Language, Culture and Power: Bilingual Families and the struggle for quality education. New York: State University of New York Press.

Dodoo, F. Nii-Amoo, and Baffour K. Takyi. 2002. "Africans in the diaspora: black-white earnings differences among America's Africans." Ethnic \& Racial Studies 25 (6):913941.

Dryfoos, Joy G., and Sue Maguire. 2002. Inside full-service community schools. Thousand Oaks, CA: Corwin Press.

El-Haj, Thea R. Abu. 2002. "Contesting the Politics of Culture, Rewriting the Boundaries of Inclusion: Working for Social Justice with Muslim and Arab Communities." Anthropology \& Education Quarterly 33 (3):308-316.

Fan, Xitao, and Michael Chen. 2001. "Parental Involvement and Students' Academic Achievement: A Meta-Analysis." Educational Psychology Review 1:1-22.

Feistritzer, C. Emily. 2011. Profile of Teachers in the U.S. 2011. Washington, DC: National Center for Education Information.

Fine, Michelle. 1993. "[Ap]parent Involvement: Reflections on Parents, Power, and Urban Public Schools." Teachers College Record 94:682-710.

Fix, Michael, and Randy Capps. 2005. "Immigrant Children, Urban Schools, and the No Child Left Behind Act. ." Migration Policy Institute, accessed February 26. http://www.migrationinformation.org/Feature/display.cfm?id=347.

Gendron, Richard. 2006. "Forging Collective Capacity for Urban Redevelopment: "Power To," "Power Over," or Both?" City \& Community 5 (1):5-22.

Gonzalez, Gabriella C. 2005. Educational attainment in immigrant families : community context and family background, The new Americans. New York: LFB Scholarly Pub.

Hong, Soo. 2011. A cord of three strands : a new approach to parent engagement in schools. Cambridge, MA: Harvard Education Press.

Horvat, Erin McNamara, Elliot B. Weininger, and Annette Lareau. 2003. "From Social Ties to Social Capital: Class differences in the relations between schools and parent networks." American Educational Research Journal 40 (2):319-351. 
Jennings, Jennifer L., and Jonathan Marc Bearak. 2014. "“Teaching to the Test" in the NCLB Era." Educational Researcher 43 (8):381-389. doi: 10.3102/0013189X14554449.

Jeynes, Wiliam. 2003. "A Meta-Analysis: The Effects of Parental Involvement on Minority Children's Academic Achievement." Education \& Urban Society 35:202-218.

Knight, Michelle G., Rachel Roegman, and Lisa Edstrom. 2015. "My American Dream." Education and Urban Society 48 (9):827-851. doi: 10.1177/0013124515589596.

Lawrence-Lightfoot, Sara. 2003. The essential conversation : what parents and teachers can learn from each other. 1st ed. New York: Random House.

Lee, Jung-Sook, and Natasha K. Bowen. 2006. "Parent Involvement, Cultural Capital, and the Achievement Gap Among Elementary School Children." American Educational Research Journal 43 (2):193-218.

Loomer, Bernard. 1976. "Two Conceptions of Power." Process Studies 6 (1):5-32.

López, G., J.D. Scribner, and Mahitivanichcha. 2001. "Redefining Parental Involvement: Lessons from High-Performing Migrant-Impacted Schools." American Educational Research Journal 38 (2):253-288.

Lunneblad, Johannes, and L. Janelle Dance. 2014. "Performativity pressures at urban high schools in Sweden and the USA." Ethnography and Education 9 (3):298-312. doi: 10.1080/17457823.2014.907746.

Mapp, K. L., and S. Hong. 2010. "Dubunking the myth of the hard to reach parent." In Handbook of School-Family Partnerships, edited by S.L. Christenson and A. L. Reschly. New York: Routledge.

Markose, Susan Jacqueline, and Alyson Simpson. 2016. "'I want them better than me': Pedagogical strategies employed by four immigrant parents in the face of perceived forms of exclusion by school authorities." Race Ethnicity and Education 19 (3):659-682. doi: 10.1080/13613324.2014.885423.

McCabe, Kristen. 2011. "African Immigrants in the United States." Migration Policy Institute, accessed September 7. http://www.migrationinformation.org/usfocus/display.cfm?ID=847 - 14 .

Mittelberg, David, and Mary C. Waters. 1992. "The Process of Ethnogenesis Among Haitian and Israeli Immigrants in the United States." Ethnic \& Racial Studies 15 (July):412-435.

Moll, Louis C., Cathy Amanti, Deborah Neff, and Norma Gonzalez. 1992. "Fund of knowledge for teaching: Using a qualitative approach to connect homes and classrooms." Theory into Practice 31 (2):132-141.

Mulgan, Geoff. 2009. "Feedback and Belonging: Explaining the Dynamics of Diversity.". Migration Information Source, accessed February 3. http://www.migrationinformation.org/Feature/print.cfm?ID=718.

Noguera, Pedro. 1996. "Confronting the urban in urban school reform." Urban Review 28 (1):127.

Olivos, Edward M. 2006. The power of parents : a critical perspective of bicultural parent involvement in public schools. Edited by Anonymous, Counterpoints ; v. 290. New York: Peter Lang.

Pasel, Jeffrey S. 2011. "Demography of Immigrant Youth: Past, Present, and Future." The Future of Children 21 (1).

Roubeni, Sonia, Lucia De Haene, Eva Keatley, Nira Shah, and Andrew Rasmussen. 2015. "“If We Can't Do It, Our Children Will Do It One Day"." American Educational Research Journal 52 (2):275-305. doi: 10.3102/0002831215574576. 
Shirley, Dennis. 1997. Community organizing for urban school reform. 1st University of Texas Press ed. Austin: University of Texas Press.

Traoré, Rosemary, and Robert J. Lukens. 2006. This isn't the America I thought I'd find : African students in the urban U.S. high school. Lanham, MD: University Press of America.

U.S. Census Bureau. 2011. Back to School 2012-2013. In Profile America: Facts for Features. Washington, DC: US Census Bureau.

Velez, Veronica Nelly. 2012. Del Coraje A La Esperanza (From Rage to Hope): A Case Study of the Development of Latina/o Immigrant Parents as Agents of Change.

Warren, Mark R., Soo Hong, Carolyn Heang Rubin, and Phitsamay Sychitkokhong Uy. 2009. "Beyond the Bake Sale: A Community-Based Relational Approach to Parent Engagement in Schools." Teachers College Record 111 (9):2209-2254.

Warren, Mark R., J. Philip Thompson, and Susan Saegart. 2001. "The Role of Social Capital in Combating Poverty." In Social Capital and Poor Communities, edited by Susan Saegart, J. Philip Thompson and Mark R. Warren, 1-30. New York: Russell Sage Foundation.

Waters, Mary C. 1994. "Ethnic and Racial Identities of Second-Generation Black Immigrants in New York City." International Migration Review 28:795-820.

Waters, Mary C., and Tomás Jiménez. 2005. "Assessing Immigrant Assimilation: New Empirical and Theoretical Challenges." Annual Review of Sociology 31:105-25.

Yosso, Tara J. 2005. "Whose culture has capital? A critical race theory discussion of community cultural wealth." Race Ethnicity and Education 8 (1):69-91. doi: 10.1080/1361332052000341006. 
TABLE 1.

SCHOOL DEMOGRAPHICS, 2007-2008

\begin{tabular}{|c|c|c|}
\hline School characteristic & Boston Elementary & $\begin{array}{l}\text { Merrimack Valley } \\
\text { Elementary }\end{array}$ \\
\hline Type of school & Public & Public \\
\hline Grades served & $\mathrm{K}-5$ & K-4 \\
\hline Students enrolled & 174 & 171 \\
\hline Staff/student ratio & 1 to 9 & 1 to 9 \\
\hline Racial composition & $\begin{array}{l}34.5 \% \text { black } \\
29.9 \% \text { Hispanic } \\
17.2 \% \text { white } \\
16.7 \% \text { Asian } \\
1.7 \% \text { Native American }\end{array}$ & $\begin{array}{l}33.7 \% \text { Hispanic } \\
28.3 \% \text { white } \\
23.9 \% \text { Asian } \\
\text { 14.1\% black } \\
0 \% \text { Native American }\end{array}$ \\
\hline $\begin{array}{l}\text { Number of countries } \\
\text { represented }\end{array}$ & 32 & 36 \\
\hline $\begin{array}{l}\text { Percent of students from } \\
\text { sub-Saharan Africa }\end{array}$ & $11.5 \%$ & $12.9 \%$ \\
\hline Low-income & $81.0 \%$ & $84.2 \%$ \\
\hline $\begin{array}{l}\text { Percentage of student } \\
\text { population eligible for }\end{array}$ & $69.5 \%$ Free $^{\mathrm{a}}$ & $72.8 \%$ Free \\
\hline free/reduced lunch & $11.5 \%$ Reduced & $11.4 \%$ Reduced \\
\hline First language not English & $51.7 \%$ & $50.0 \%$ \\
\hline $\begin{array}{l}\text { Limited English Proficient } \\
\text { (LEP) }\end{array}$ & $32.8 \%$ & $45.7 \%$ \\
\hline Surrounding area & $\begin{array}{l}\text { Residentially stable, white } \\
\text { middle-class } \\
\text { neighbourhood }\end{array}$ & $\begin{array}{l}\text { Residentially mobile, white } \\
\text { working class } \\
\text { neighbourhood }\end{array}$ \\
\hline Special programs & $\begin{array}{l}\text { Low-incidence Sheltered } \\
\text { English Immersion } \\
\text { Music Program }\end{array}$ & $\begin{array}{l}\text { Low-incidence Sheltered } \\
\text { English Immersion } \\
\text { City strings program }\end{array}$ \\
\hline NCLB Designation & Needs Improvement & Needs Improvement \\
\hline
\end{tabular}


TABLE 2.

Demographics of African Parent Participants

\begin{tabular}{lll}
\hline Characteristic & Boston Elementary & Merrimack Valley Elementary \\
\hline $\mathrm{n}$ & 7 & 10 \\
Average no. of children & 3.4 & 3.3 \\
Two parents at home $^{\mathrm{a}}$ & $71 \%$ & $100 \%$ \\
Education level $^{\mathrm{b}}$ & $14 \%$ No School & $10 \%$ No School \\
& $14 \%$ Mid. School & $60 \%$ High School \\
& $57 \%$ High School & $20 \%$ Associates \\
Countries of origin & $14 \%$ Associates & $10 \%$ Bachelors \\
& Liberia & Cameroon \\
& DR Congo & Kenya \\
& Somalia & Ghana \\
Initial entry visas & Ethiopia & Zimbabwe \\
& Guinea Bissau & Liberia \\
Average years in US (Range) & Nigeria & Diversity \\
Percent 'fluent' in English (no & Diversity & Refugee \\
English) & Refugee & \\
Percent Employed & $7.1(1-19)$ & $5.6(2-13)$ \\
Percent in service jobs & $57 \%(0 \%)$ & $90 \%(0 \%)$ \\
Percent in public housing & $57 \%$ & $100 \%$ \\
Percent homeowners & $71.4 \%$ & $90 \%$ \\
Percent Christian (Muslim) & $42.9 \%$ & $100 \%(0 \%)$ \\
\hline
\end{tabular}

${ }^{a}$ Both of the single parents at Boston Elementary lost their spouses in the war in Liberia. Further, one parent at Merrimack Valley lost his wife to cancer after being interviewed for the study.

${ }^{\mathrm{b}}$ Due to rounding, may not add to 100 per cent 
TABLE 3.

Sub-SAHARAN African (SSA) AND OTher IMMigrant PARTICIPATION IN Elementary SCHOOLS (K-6) IN THE UNITED STATES

\begin{tabular}{|c|c|c|}
\hline & SSA $(n=33)$ & Other Migrants $(n=796)$ \\
\hline Attended school meeting in past year & $77.6 \%$ & $77.4 \%$ \\
\hline Visited child's class in past year & $80.1 \%$ & $75.6 \%$ \\
\hline $\begin{array}{l}\text { Phoned or spoken with child's teacher/counselor in } \\
\text { past year }\end{array}$ & $67.5 \%$ & $67.4 \%$ \\
\hline Volunteered to help at child's school in past year & $36.9 \%$ & $32.4 \%$ \\
\hline Check homework often & $82.4 \%$ & $79.67 \%^{\mathrm{a}}$ \\
\hline Hold expectations for college completion or more ${ }^{b}$ & $96.1 \%$ & $91.6 \%$ \\
\hline
\end{tabular}

Notes: Data is weighted.

${ }^{\mathrm{a}} \mathrm{n}=795$

${ }^{\mathrm{b}}$ Calculated as an average of the percentages for two children

Source: New Immigrant Survey. 